\title{
Short Notes on Capacity Building Workshop in Post-Conflict Regions- 28 July 2020
}

\section{Prof. Dr. Ahmet Sedat Aybar ${ }^{1}$}

Marco Di Donato: The presentation I will make consists of the preparation process of the Higher Education Report in Libya published by UNIMED and what it expresses. First of all, I would like to talk about the method of the report; Both qualitative and quantitative methods were used. The data obtained were revealed by swot analysis. As a sample, 18 Libyan Universities were used. Four main considerations were taken into account when choosing the sample; the size of the institution at the national level, its geographical distribution, the financial balance between beneficiaries and non-beneficiaries of the European Union (EU) financial support programs, Universities that were in contact with UNIMED before. Interviews were conducted focusing on issues such as the security of the country, the national education system, legal reforms, the international cooperation performance of the University and its role in society. Finally, a draft of the study was prepared and sent to Universities for their approval, addition / removal or interpretation (I have to admit that we had a hard time getting approval from Arab sources). We obtained the Swot Analysis (strong, weak, opportunity, threat) output to create a strategic plan for the system. According to this analysis, we have seen that EU project calls are a strong element in education sector capacity building; leaders changing at optimum level, quality of accreditation processes and financial autonomy are the weak elements; the acceptance that universities can make positive changes in society is an opportunity element; and finally, political instability along with security problems are a threat to capacity building. I emphasize once again; Libyan Universities are there for any kind of cooperation you can think of, despite all the problems that exist. They are waiting. The strong influence of EU programs in the region cannot be denied. Changing leaders in financial autonomy and management have weakened the development of the education sector and disrupted the process.

\footnotetext{
${ }^{1}$ Prof. Dr., Head of Africa Research Center (AFRIKAM), Istanbul Aydın University, sedataybar@aydin.edu.tr, orcid.org/0000-0002-2544-4332

*Received: 11.01.2021, Accepted: 25.02.2021.

DOI: 10.17932/IAU.FCPE.2015.010/fcpe_v07i1005
} 
UNIMED did not adopt a top-down approach while preparing this report, it really continued to work in cooperation and mutual solidarity, hand in hand. Therefore, we can name the approach UNIMED approach. As a result of the report, UNIMED made some suggestions for capacity building in the Libyan education sector, today I will share with you only four (4) recommendation titles without going into details. I hope that we will have the opportunity to discuss these suggestions in depth in the future, because when there is discussion, suggestions can be developed and turned into opportunities. Otherwise, it would not be possible to improve these determinations.

1- Governance and Autonomy:

a. To develop an effective University governance system using benchmarking method (bench-marking system).

b. Supporting the definition of a common national strategic vision for the Higher Education System with the enhanced role of the University Presidents Council.

c. Increasing the academic autonomy of universities

d. Increasing the financial autonomy of universities

2- Quality Assurance: This recommendation title has been undisputedly accepted and supported by our collaborators in Libya.

a. Ensuring the standards of the educational performance of academic staff.

b. Providing quality education and training

3- International Cooperation:

a. Including Libyan Universities into International platforms.

b. Increasing the research performance of Libyan Universities

c. To inform Libyan Universities about research fields, especially in engineering, social sciences, information systems, environmental sciences, health and medicine.

4- Universities in Society:

a. Universities as an institution have a respected place in the society. Higher education is an element that serves society. In this context, community and university cooperation support must be obtained in 
the progress of both the education sector and other sectors that are lacking and need to be developed after the conflict.

b. A win-win strategic plan should be created by considering the Ministry of Education, research centers, the stakeholders of the industrial market and all other community components.

UNIMED identified the problem, revealed the situation, offered solutions, but where to start? When we asked this question to Libyan Universities, the answer they gave was that we can start from anywhere. UNIMED's answer was Health. According to our findings, capacity building is focused on education and training, but the most important emphasis should be on research and health. Therefore, the first step should be taken in the field of health and health education. This determination of UNIMED should not be considered in connection with COVID-19. Health is a very important area that should focus on interest and attention in every period, it existed also before COVID-19.

We are just at the beginning. We can do good work with the capacity building action in Libya. In this sense, Libyan Universities are ready, waiting for our support and cooperation. Our aim; Activating Libyan Universities in the Mediterranean Region to become sought-after stakeholders in internationalization and cooperation. Finally, we will update the data of the Libya Report we have prepared in December and share it with you again.

Dr. Edna Adan Ismail: I worked for the World Health Organization for many years, then I returned to my country and the first thing I did was to build a hospital. Although my country Somaliland declared its independence in 1991, it still maintains its existence under Somalia's yoke. Until 1991, the civil war had destroyed $95 \%$ of hospitals, schools and living spaces. During this period, there were migrations from the country to out. When peace and tranquility returned to our lands, many people who wanted to return to their homeland came back and tried to find an accommodation again. In this process, the construction of The Edna Adan Hospital in Hargeisa was completed in March 2002, and we built a hospital within the bounds of possibility us. Once after the conflict, there was no material or equipment needed in Somaliland; He became an employee with quality. As in every sector, there was a lack of qualified human resources, especially in the health sector. During the process, we make an effort to train nurses and midwives. Although our number and possibilities have 
increased from year to year, we still suffer.

When we look at the education sector, it took us a long time to talk about Universities. While completing compulsory education posed great difficulties, families were hesitant to send their children to the University. Apart from this, with the 2020 COVID-19 pandemic, we have seen more clearly that the opportunities of the University are not sufficient today. While students all over the world can continue their lessons with online education from their homes, there are students in Somaliland who do not have electricity at home, let alone the laptop internet. There are such students that they have never seen a mobile phone or a laptop in their lives... This is not fiction, it is real. In other words, the concepts of internet or distance education are quite new for us. So, distance education can only be implemented for wealthy students. What about others? Although we could not provide technological equipment to all students, we made our libraries open $24 / 7$, provided them to use the internet for free. Fortunately, as of 15 July 2020, that is, in the last 2 weeks, we have reopened our schools as there has been a decrease in the number of cases and resume on face-to-face education. The most important reason for this is that distance education in health sciences is not possible as in social sciences. Students should be able to touch, smell, feel. Otherwise, their training cannot take place.

I am very happy to be able to talk to you today. I have a message that I want to convey; Thank God that today we can fight the pandemic in one way or another. However, we do not know what we will encounter when we turn the corner... We must prepare for an urgent situation. We need to prepare ourselves in every field against disasters such as natural disaster, nuclear attack, another kind of pandemic, etc. We need to review and prepare everything from distance education to intensive care units in hospitals. Yes, the Coronavirus has caused a lot of damage, but it gave us a warning: prepare yourself for unexpected events.

We must learn from each other; We should account for what we shared, what we taught. You should know that; Somaliland is a safe and peaceful place. Anyone can come and visit with peace in mind. We are especially pleased to welcome retired professors because our biggest deficiency is that there are no qualified professionals in their field. We make an effort to train qualified human resources and, in this sense, we need retired teachers. I hope you will listen to this call.

I would like to end my remarks with one of the greatest legacies left to me by my esteemed father, who is known as the health father of Somaliland; 
If you do not do what you do with your heart and conscience, you cannot be successful in it! We offer my respect, love and thanks and look forward to your cooperation in the short and long term.

HRN Zolani Mkiva: Greetings to everyone from South Africa.

What should we do for a solid future and a better tomorrow? What do we spend our resources and our time and energy on? While seeking answers to these questions, we must realize that education is the most important instrument of social change and transformation. Education of young people and children is the future of societies, it is their tomorrow.

Another version of the Somaliland reality is also valid in here; It would be a great mistake to think of the African continent as Europe and America, because opportunities in these lands are always limited and scarce. Distance education, which is an inevitable method in the Covid-19 process, is very difficult in these lands. There are young people here who have never seen a laptop or a mobile phone in their lives and have never searched on Google. Imagine the regions where the industrial revolution has never been...

So, what should be done? How should capacity building be undertaken? I think it will be possible with the cooperation of asset owners. If a strategically successful future is to be built, we must be together as wealthy people and move forward with common sense. Wealthy people should not be blind or ignore poverty and famine. In this sense, solidarity is very important. We should see each other in a spirit of cooperation. We must not continue to be silent and blind. At the same time, we must learn from each other. What can we do? We should exchange the exchange programs of our own system, introducing students to each other.

We must give importance to culture and keep the values alive. All cultural values are important, we just cannot continue to cherish our own culture. It should not be forgotten that culture and education are like two sides of a coin, they are never inseparable. Following culture, language is another key and critical word. Of course, there should be a common language for effective and practical communication, but it would not be the right attitude to suppress or ignore other languages. We must keep alive the languages of the world and give them the value they deserve. Culture, language and education are dynamic and integrated.

We call it continuous education, but how about education? Of course, quality education. The gaps in the existing system should be filled, and 
young people should be directed to what is good and beneficial. You may know, in this region, young people have fallen prey to drugs and various bad habits. Why is that? Because of the gaps in education. Due to the shortcomings, young people are turning to these places and they do not spend their time on useful things or scientific knowledge. If you want improvement and return in the long run, you should invest in people.

Prof. Dr. Sabahudin Hadzialic: Consider the question of free society or healthy society; In order to have a healthy society, the media in society must be free. Talking about the capacity building of any sector where there is no freedom of expression is like building a building without a foundation. When we look at the example of Bosnia and Herzegovina, there is a great pressure and censorship in the media sector due to the practices of the current government. The social situation after the war caused the media sector to become fragmented and biased. Journalists could no longer move pens freely; it became impossible to write against the government, their writing was not published if they tried, professional ethics were violated and their careers were blocked; journalists were attacked both verbally and physically. Journalists were politically bound to power. These pressures continue today, and journalists' unemployment rates are very high. Active employees, on the other hand, have poor working conditions. In this context, I would like to highlight five (5) important criteria for interacting and building ethical understanding in society:

1- Common values in the ethical system; democracy

2- Harmonization of rights and interests with other people's obligations

3- An ethical system should work for justice

4- Freedom of choice and compliance with the responsibilities of others

5- Right to equal obligations

Prof. Dr. Titumir Mahmud: Exactly what my heart is feeling, what my mind is thinking I wanted to shape this speech according to the moment in order to express it, I did not prepare a presentation. Our main speech as Universities before capacity building in order not to take your time and I would like to share with you seven (7) points that I think should focus on; 1 - University is a place to make Innovation.

2- University is a place of teaching history. How should we focus 
on the concept of citizenship? Is it transformational or solidarity citizenship?

3- University is the most important building block of talent building. So how do we handle talents?

4- Versatility. What kind of versatility are we talking about? Are we really aiming for a future for everyone? How do we achieve this? The phenomena dictated by some countries are today called multiculturalism, do we mean such a perception by the versatility?

5 - Benefit. What kind of community good are we talking about?

6- Are we trying to understand the society itself? What methods are we trying to do this? Are we doing it by focusing on the market or the human essence?

7- Social Solidarity. What kind of an individuality concept do we have? What do we mean by the self?

Now that I can make my voice heard by two global forces such as the Mediterranean University Association and the Eurasian University Association, I would like to state that the definition of the University must be made. What is a university? What is its function? What is the reciprocal by the community? It is of great importance to be able to answer all of these.

Dr. Liz Ng'ang'a: According to the majority, talent in education means a gift, academic success or performance. But no, talent means contradiction; talent in education, is critical thinking ability and leadership skill. Each time we raise discussion topics that will address education in general, but we are not talking about academic education and talent. We must address the issue of talent by emphasizing the importance of scientific knowledge and unity. Because in the future, talent management will emerge as one of the key concepts within capacity building.

Dr. Aydın Nurhan: Each country's educational steps are different. The education system is shaped by its own language, its own social dynamics and its own traditions. In the Republic of Turkey, educations foundation laid by Mustafa Kemal Atatürk. To those who want to take the path followed in the education system as an example from neighboring countries, he answered "No, you should develop the most appropriate education system for your country" and underlined how important it is for societies to create their own educational strategies. Every country has its 
own culture. This culture constitutes the educational purpose of that country. When we look at the Ottoman period, the aim of education was shaped by the desire to create a nation. In the first years of the Republic; It was to train bureaucrats. When we look at the next era, we can see that the only purpose of education is to train people for the private sector. In Turkey both secular and spiritual education are being tried together but something has been done wrong. My suggestion is to settle an education system that includes five (5) basic elements. What are those elements; sports, music, mathematics, history and mother tongue. The primary subject and contents that should be given within the education are these five elements that I mentioned, the rest is not very important. These five elements should be taught by the end of high school education. The child, who has received in-depth education on these subjects, can then be guided in the education life by evaluating the interest and ability. Of course, religion is also an important factor. I think it should not be kept away from education. Because humans also need spiritual things. Unfortunately, the quality of teachers in Turkey is quite low and this is very upsetting. Not only in Turkey but all over the world teacher quality is too low. So much so that teachers are incapable of using their mother tongue properly and correctly. This problem should be resolved. Teachers should have their own educational books. Students should be given the opportunity to discuss. The student should be released from the listening position. In this way, students will be able to be guided critically and then generate ideas themselves. Finally, I would like to touch on the perspective dimension of the five elements I mentioned; sport is an international branch, so is mathematics. You can find the most talented athlete or the smartest math brain and educate them according to international values. You cannot have a completely international perspective on music; You can take some values and teachings as examples, but you have to keep your own tunes alive. Hence, music is semi-national and semi-international. Language and history are completely national. You prepare and present content and integrity yourself.

Mr. Habimama Emmanuel: The education sector in Rwanda was restructured after the 1994 Genocide, which was one of the biggest massacres in human history. The greatest effort has been devoted to laying the foundations of the universal education system, and this effort has resulted in building an education system that encourages critical thinking and is also self-sustaining. I can clearly state that there have been 
significant changes in Rwanda. So much so that while there was only one (1) university in Rwanda in 1995, there were 40 universities in 2019.

Mr. Chelopas Wanyonyi Chelosi: In conflict regions, generally inequality in resource allocation is one of the main causes of conflict. Another is the welfare level, so that often the driving force behind the conflict is wealth injustice. The issue of hunger and food insecurity is one of the reasons that lead to conflict, as can be understood from the example of the Bread Revolution (caused by the increase in food prices) in North Africa. Conflicts, on the other hand, may appear in forms such as civil protests, riots, discontent, segregation, alienation, hunger or pandemic. During the conflict comes an immoral degradation of social systems. Food insecurity of the population leads to difficulties such as malnutrition. For some reason, the first sector to be affected is the agricultural sector, productive systems are destroyed in conflict. Thus, the movement of goods and services is disrupted, and the input, output and access of agricultural products are affected. Infrastructure and education departments, which are the drivers of economic growth, are also affected by the proceedings of the conflict. The post-conflict education sector should focus on rebuilding key skills lost or displaced during the conflict. When we look at the stages of the post-conflict education sector in the short, medium and long term; In the short term, it is seen that there is a search for solutions regarding the ceasefire declaration, the resettlement of the population in the agricultural areas and the end of the conflict.

The post-conflict education sector should focus on rebuilding key skills lost or displaced during the conflict. When we look at the short, medium and long-term stages of the Capacity Building Workshop in the PostConflict Regions on July 28, 2020, where the post-conflict education sector passes; In the short term, it is seen that there is a search for solutions regarding the ceasefire declaration, the resettlement of the population in agricultural areas and the end of the conflict. To make the system work in the medium term and to rebuild agricultural marketing systems In the long run, the processes of developing technical agricultural skills are of great importance in order to eliminate the causes of sustainable development and conflict. To list the areas that are the special focus of the education sector in the post-conflict regions; advocacy and negotiation skills, finance management skills, technical skills, organizational development skills, and business development skills.

Finally, I would like to touch upon the agricultural sector, which I attach 
great importance to. I think it is necessary to focus on the components of food security in post-conflict regions. What are these components; food availability, food accessibility, food use and nutrition.

HE Williams Nkurunziza: I will not share with you the results of an academic study today. I want to shape my speech through the narratives of valuable speakers who took the floor before me. The training of Rwanda after the conflict was mentioned. While no one hopes that this country will be able to rise again, Rwanda has made significant progress in education and has become a model country. How did he do that? He succeeded with the factors of leadership and national vision-oriented vision. Just as there is a need for a leader to lead the mass events, a leader who can mobilize the society, identify needs and develop a strategy is needed after the conflict. This leader must have a vision, be able to draw a path, and at the end of that path, the society must be able to reach the goal. If this goal is to be sustainable in education, absolutely every child should be given access to education, and their learning should be ensured. Because education itself may die one day or people may have enough capacity, but if every student has the right to access education, the system will surely revive itself in some way.

Between 1982 and 1994, education was not a right in my country. Individuals who could get an education were people of the upper class or an opportunity gifted to them by politicians. After 1994, education policy was developed and education started to be seen as a right for capacity building in society. Children could receive education because they were given the opportunity to receive. I want to give an example; I was in England in 2014. I learned that a student was sent to Birmingham University for a mining engineering department with a government scholarship. I went personally and chatted with those students. I was very curious about how and why the students took advantage of this opportunity. Although one of the students made no application, he said that he was called one day by the officials of Short Notes 10 for the Capacity Building Workshop in the Post-Conflict Regions of his village on July 28, 2020, and that he was entitled to receive this scholarship. This student was a young peasant who had excelled throughout his education life, that is, until that day, who had an interest and skill in reading and acquiring a profession, but had no acquaintance with high authorities. In other words, although he did not have an acquaintance to favor him, he was able to take advantage of such an opportunity. This example actually tells us a lot about 
how to transform a society, how to improve and develop the education sector. Think of such a system that both detects the successful and the needy. This means that the system is a just and equal education system that recognizes the potential power and supports science. Achieving all of these should not be easy, but democratizing education, the presence of a forward-thinking leader and having a vision in the focus of national vision are the indispensable factors for the education sector to stand up in postconflict regions today.

Figure 1: Focus of Post-Conflict

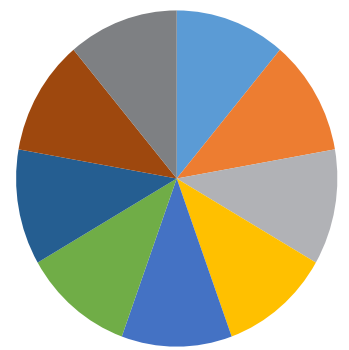

- Healt

Qualified

-University Description and

- Model Country

-5 Elements (Music, Sport, Math,

History and Mother Tongue)
- Preparing for Emergency

Media and

- Leader and Vision

- Food and Agriculture

Based on the speeches of the speakers, it is a graphic of the major issues that need to be focused on capacity building in post-conflict education in conflict zones. 